\author{
DOI: 10.12731/wsd-2018-3-24-40 \\ УДК 616.345-006-036.22(574.41)
}

\title{
КОЛОРЕКТАЛЬНЫЙ РАК: ЭПИДЕМИОЛОГИЯ И ФЕНОТИП ПАЦИЕНТОВ В РЕСПУБЛИКЕ ХАКАСИЯ
}

\section{Штыгашева О.В., Агеева Е.С., Балобина Н.С., Манашева Д.И.}

Состояние вопроса. Риск развития колоректального рака (КРР) повышается при длительности течения $B 3 K$, а риск малигнизаџии полипа возрастает с величиной полипа. Выявление и мониторинг гиперпластических и аденоматозных полипов играет важную роль в превенциии и ранней диагностике КРР. Цель - изучить эпидемиологические особенности КРР в Хакасии и частоту стратифииированных факторов риска заболевания по данным витального анамнеза для формирования когорты пациентов, которые должны быть исследованы в первую очередь.

Методы. Анализ заболеваемости; локализации, морфологии опухоли, пятилетней выживаемости за период 2006-2015 годы. Ретроспективный анализ историй болезней. Анкетирование по данным витального анамнеза. Достоверность различий между двумя группами пациентов оченивалась с применением критерия соответствия ( $\chi 2)$ при $p<0,05$. Корреляичионный анализ проводили с применением критерии Спирмена при $p<0,05$.

Результаты. В период 2011 по 2015 год - увеличилось число пациентов с КРР состоящих на диспансерном учете, по сравнению с периодом 2006-2010 год. Преобладающим типом является аденокариинома разной степени дифференцировки, локализация в прямой кишке была более частой, чем в ободочной кишке. В период 2011-2015 2. увеличилась доля пациентов с 1-2 стадией заболевания и увеличение пятилетней выживаемости пациентов после установления диагноза. Средний возраст больных КРР - 69 (61-77) лет. Средняя продолжительность жизни у женщин превышала у мужчин на десять и более лет.

Риск развития КРР у пациентов с ожирением был в 1,5 раза выме, чем у людей с нормальной массой тела. Гиподинамия у мужчин встречалась в 5 раз чаще, курение в 2 раза больше, чем у женщин. Среди женщин с КРР имели сахарный диабет 2 типа в 4 раза, холецистэктомию в 2,5 раза, сочетанную патологию в 3 раза и длительный анамнез по ВЗК 5 раз больше, чем мужчин. 
Заключение. Увеличение показателей заболеваемости КРР в Республике Хакасия обусловлено увеличением первичной заболеваемости, в том числе за счет активно выявленных пачиентов; увеличением доли пачиентов с впервые установленным диагнозом КРР на 1-2 стадиях заболевания, повышением пятилетней выживаемости пациентов.

Ключевые слова: колоректальный рак; рак прямой кишки; рак ободочной кишки; аденокарцинома; факторы риска; ожирение.

\section{THE COLORECTAL CANCER: EPIDEMIOLOGY AND PHENOTYPE OF PATIENTS OF THE REPUBLIC OF KHAKASSIA}

\section{Shtygasheva O.V., Ageeva E.S., Balobina N.S., Manasheva D.I.}

Background. The risk colorectal cancer (CRC) increases with the duration of the course inflammatory bowel disease (IBD), the risk polyp malignancy rises with the size of polyp. The examining and monitoring of hyperplastic and adenomatous polyps plays important role in predictive and early diagnosis of $C R C$. The aim is research the epidemiological features CRC of Khakassia and frequency of stratify factors of disease risk due to data of vital anamnesis is to form a cohort of patients which must be examine at first.

Methods. It analyzed of disease, localization, morphology of tumor, fiveyears of survival, during 2006-2015. The retrospective analysis of disease of stories. The questionnaire on the data of vital anamnesis. Statistical significant between groups of patients was estimated using the conformity criterion ( $\chi 2)$ at $p<0.05$. The correlation analysis was using Spearmen criterion at $p<0.05$.

Results. From 2011-2015 the amount of patients with CRC consisting of dispensary registration increased compared with 2006-2010. The dominant type was adenocarcinoma different study mature which localized in the rectum more than the colon. During 2011-2015 the amount of patients with disease 1-2 studies and five-year survival after the disease is diagnosed are increased. The middle age of patients was 69 (61-77) years. Women, as a group lived longer than men as much as 10 years. The patients with obesity had risk of CRC more in 1.5 times compared with patient's normal body weight. The men with low physic activity were in 5 times, smoking in 2 times more compared with women. Prevalence of women and type 2 diabetes mellitus was in 4 times, with cholecystectomy in 2.5 times, with concomitant pathology in 3 times, with prolonged anamnesis inflammatory bowel disease in 5 times compared with men in patients with CRC. 
Conclusion. Increase in morbidity CRC in Republic of Khakassia due to the increase in primary incidence, including at the expense of actively identified patients, increase in patients with a first diagnosis of CRC in 1-2 stages, increased five-year survival of patients.

Keywords: colorectal cancer; rectum cancer; colon cancer; adenocarcinoma; factors risk; obesity.

\section{Введение}

Колоректальный рак (КРР) с аутосомно-доминантной формой наследования составляет 4-6\%, а спорадический КРК - 94-96\% случаев [12]. Этот факт детерминирует выделение двух целевых групп для скрининга заболевания [11]. В «группе практически здоровых» независимым фактором риска является возраст. В «группу высокого риска» включены пациенты с воспалительными заболеваниями кишки (ВЗК): язвенный колит, болезнь Крона, шистосомоз с вовлечением толстой кишки, пациенты с аденомой толстой кишки в анамнезе и/или имеющие ближайших родственников, у которых в анамнезе были КРР или аденома толстой кишки $[8,11]$. К предраковым заболеваниям толстой кишки, независимо от возраста пациента, относят единичные и множественные аденомы (полипы) толстой кишки. Риск развития КРР повышается до 15\% при длительности течения ВЗК более 30 лет, а риск малигнизации полипа возрастает с величиной полипа [11]. Выявление и мониторинг гиперпластических и аденоматозных полипов играет важную роль в превенциии и ранней диагностике КРР.

Скрининг КРР - сложное мероприятие, имеющее различные варианты организации, требует определенных усилий от пациентов и существенных затрат системы здравоохранения на проведение диагностики [11]. В связи с этим, формирование когорты пациентов, которые должны быть направлены на исследование в первую очередь, является важной задачей.

Цель исследования - изучить эпидемиологические особенности КРР в Хакасии и частоту стратифицированных факторов риска заболевания по данным витального анамнеза для формирования когорты пациентов, которые должны быть исследованы в первую очередь.

\section{Материалы и методы исследования}

Исследование проводилось на клинической базе университета ГБУЗ Республики Хакасия «Республиканский клинический онкологический диспансер». Проведен анализ статистических показателей (заболеваемость и общая заболеваемость; стадия, локализация и морфологические признаки 
опухоли, пятилетняя выживаемость) за период с 2006 по 2015 годы. Изучены: регистрационная карта больного злокачественным новообразованием (ф. 030/ГРР), извещение о больном с впервые в жизни установленным диагнозом рака или другого злокачественного новообразования (ф. 090/y), статистический талон для регистрации заключительных (уточненных) диагнозов (форма N 025-2/y). Всего 1690 случаев (100\% пациентов с колоректальным раком в Республике Хакасия за этот период времени). Ретроспективный анализ историй болезней 180 пациентов, отобранных методом случайной выборки (10,6\% от всех пациентов с колоректальным раком) проведен для оценки клинических признаков заболевания. Анкетирование 66 пациентов с КРР для изучения факторов риска по данным витального анамнеза.

Критерием отбора было добровольное информированное согласие на участие в анкетировании и верифицированный диагноз КРР во всех случаях.

Статистическая обработка проводилась в пакете прикладных программ BioStatPro 5.9.8. Применялись непараметрические методы. Достоверность различий между двумя группами пациентов оценивалась с применением критерия соответствия $(\chi 2)$ при $p<0,05$. Корреляционный анализ проводили с применением критерии Спирмена при $\mathrm{p}<0,05$.

\section{Результаты собственного исследования}

Согласно статистическим данным, в период с 2006 по 2010 год на диспансерном учете состояло 726 больных КРР, из них 47,5\% (n=345) с локализацией в ободочной кишке и $52,5 \%(\mathrm{n}=381)$ - в прямой кишке. В период с 2011 по 2015 год на учете состояло 964 пациента с КРР $(\mathrm{p}<0,05)$, из них $47,2 \%(\mathrm{n}=455)$ с локализацией в ободочной кишке и $52,8 \%(\mathrm{n}=509)$ - в прямой кишке. При сравнении конечных точек исследования (2010 и 2015 годы) установлены статистически значимые различия. В период с 2006 по 2010 годы средний показатель заболеваемости составил 12,2 (рак прямой кишки) и 11,3 (рак ободочной кишки) на 100000 населения, а в период с 2011 по 2015 год, аналогичные показатели составили 22,0 (рак прямой кишки) и 25,8 (рак ободочной кишки) на 100000 населения (рис. 1).

Показатель больных, выявленных активно, в 2006 году составлял 8,2\% при раке ободочной кишки, 4,5\% при раке прямой кишки. Через пять лет, в 2011 году, аналогичный показатель для рака ободочной кишки составил $8,8 \%$, а для рака прямой кишки - 16,8\% (в 3,7 раза выше). Через 10 лет, в 2015 году, рак ободочной кишки активно был выявлен у 16,4\% пациентов, а рак прямой кишки - у 13,3\% (рис. 2). 


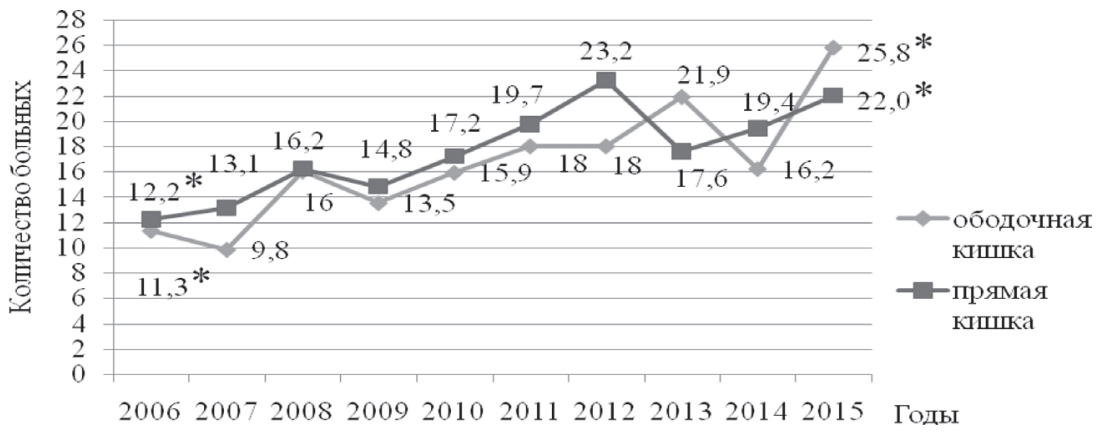

Рис. 1. Динамика показателей заболеваемости КРР с впервые установленным диагнозом на 100 тыс. населения в Республике Хакасия с 2006 по 2015 годы, где *p - уровень статистической значимости, $\mathrm{p}<0,05$

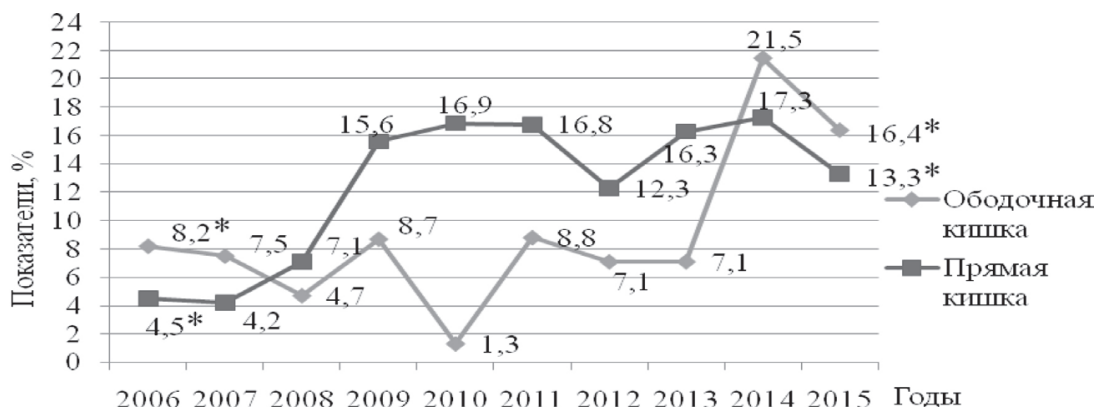

Рис. 2. Динамика показателей активно выявленных случаев КРР, от числа заболевших впервые, в Хакасии, в период с 2006 по 2015 годы, \%, где * $\mathrm{p}$ - уровень статистической значимости, $\mathrm{p}<0,05$

При сравнении суммарных показателей двух пятилетий отмечается стабильность структуры пациентов по локализации опухоли (рак прямой кишки составил $52,5 \%$ и $52,8 \%$, соответственно, а рак ободочной кишки $-47,5 \%$ и 47,2\%, соответственно), преобладающий морфологический тип опухоли - аденокарцинома разной степени дифференцировки $(92,5$ $\%$ и $78,2 \%$ соответственно). В тоже время фиксируется прирост абсолютного числа пациентов с КРР на $32,8 \%$, что может быть обусловлено следующим. Структура КРР по стадиям выявления заболевания претерпела изменения. Во втором пятилетии (2011-2015 годы), увеличилась доля первичных пациентов, с диагнозом, выявленным на 1-2 стадии заболевания. Прирост таких пациентов составил 8,8 \%, в сравнении с предшествующим пятилетием 2006-2010 годы (рис. 3). Не смотря на высокий 
показатель выявления КРР на 4 стадии (рис. 3), фиксируется увеличение пятилетней выживаемости пациентов после установления диагноза.

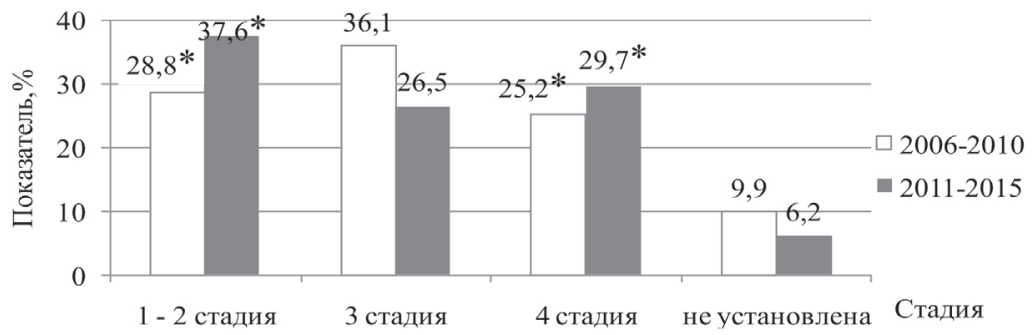

Рис. 3. Динамика показателей заболеваемости КРР по стадиям в момент установления диагноза впервые, в Республике Хакасии, в период 2006-2010 гг. и 2011-2015 гг., \%, где *p - уровень статистической значимости, $\mathrm{p}<0,05$

Учет пятилетней выживаемости является наиболее достоверным методом определения степени прогресса болезни и ее прогноза. В Хакасии наметилась тенденция к увеличению пятилетней выживаемости пациентов после впервые установленного диагноза в 2015 году, по сравнению с 2011 и 2006 годами. В 2006 г. у пациентов с поражением ободочной кишки показатель составил 47,5\%; прямой кишки - 39,1\%; 2011 г. у пациентов с поражением ободочной кишки - 45,6\%; прямой кишки - 40,6\%; 2015 г. у пациентов с поражением ободочной кишки - 51,6\%, прямой кишки 41,6\%. Пятилетняя выживаемость пациентов при раке ободочной кишки прогрессивно превышала аналогичный показатель при раке прямой кишки за весь период наблюдения (но также не преодолела 60\% порог). Увеличение пятилетней выживаемости при КРР, кроме улучшения своевременной диагностики заболевания, может быть связано с изменением лечебных технологий. В Хакасии в период 2011-2015 годы стали использовать более агрессивное хирургическое лечение пациентов с КРР, включая поздние стадии заболевания, что обеспечивало большую радикальность. У пациентов с метастатическим КРР, таргетная терапия химерными моноклональными антителами класса IgG1, специфично связывающимися с EGFR, при экспрессии EGFR и диким типом RAS, проводилась на основании тестирования k-RAS мутации $[9,18,19,20]$. Также использовались рекомбинантные гиперхимерные гуманизированные моноклональные антитела, которое селективно связываются с VEGF и нейтрализует его.

Возраст. Динамика заболеваемости колоректальным раком в различных по возрасту и полу группах населения свидетельствует о том, что у 
лиц обоего пола риск возникновения КРР увеличивается в возрасте 40-59 лет, затем имеет тенденцию к удвоению с каждой декадой жизни человека [1]. Средний возраст заболевших колоректальным раком в странах СНГ был минимальным в Туркмении, Киргизии и Азербайджане (59-62 года) и максимальным в России и Армении (65-68 лет). Около 85\% случаев колоректального рака приходится на возраст старше 55 лет. Рак данной локализации крайне редко встречается у лиц до 30 лет, а заболеваемость резко возрастает с увеличением возраста, достигая максимума в 70 лет и старше [4]. По данным Я.С. Циммермана, в России до 75\% всех случаев колоректального рака приходится на возраст 40-59 лет, 16-18\% - 20-39 лет, $20 \%$ - после 60 лет [12]. В связи с «постарением» населения во всем мире прогнозируется значительное увеличение количества случаев колоректального рака в ближайшие два десятилетия [11].

Мы подтвердили, что возраст является фактором риска развития колоректального рака. Средний возраст больных КРР в Хакасии на протяжении последнего десятилетия составляет - 69 (61-77) лет. При сравнении показателей заболеваемости в трех возрастных группах отмечался статистически значимый рост числа больных, ассоциированный с увеличением возраста. Доля пациентов возрастной группы 20-39 лет составила 0,7-4,4\% всей когорты больных. Число больных в «группе 40-59 лет» по сравнению с «группой 20-39 лет» увеличилось в 11,7 раз. Число больных возрастной «группы более 60 лет» в 3,3 раза больше, чем больных в «группе 40-59 лет» (табл. 1).

Таблицуа 1.

Распределение пациентов (\%), с установленным диагнозом колоректального рака, по трем возрастным группам в Республике Хакасия с 2006 по 2015 годы

\begin{tabular}{|c|c|c|c|c|c|c|}
\hline \multirow{2}{*}{ Возраст } & \multicolumn{2}{|c|}{$\mathbf{2 0 - 3 9}$ лет } & \multicolumn{2}{c|}{$\mathbf{4 0 - 5 9}$ лет } & \multicolumn{2}{c|}{$>\mathbf{6 0}$ лет } \\
\cline { 2 - 7 } & $\begin{array}{c}\text { Абсолютное } \\
\text { число }\end{array}$ & $\begin{array}{c}\text { Доля, } \\
\text { Го }\end{array}$ & $\begin{array}{c}\text { Абсолютное } \\
\text { число }\end{array}$ & $\begin{array}{c}\text { Доля, } \\
\text { \% }\end{array}$ & $\begin{array}{c}\text { Абсолютное } \\
\text { число }\end{array}$ & $\begin{array}{c}\text { Доля, } \\
\%\end{array}$ \\
\hline 2006 & 6 & 4,4 & 28 & 20,7 & 101 & 74,9 \\
\hline 2007 & 1 & 0,7 & 29 & 22,0 & 102 & 77,3 \\
\hline 2008 & 5 & 2,7 & 39 & 21,5 & 138 & 72,8 \\
\hline 2009 & 2 & 1,3 & 33 & 21,3 & 120 & 77,4 \\
\hline 2010 & 2 & 1,1 & 41 & 22,9 & 136 & 76,0 \\
\hline 2011 & 4 & 2,1 & 55 & 28,6 & 133 & 69,3 \\
\hline 2012 & 4 & 1,8 & 46 & 21,2 & 167 & 77,0 \\
\hline 2013 & 3 & 1,4 & 50 & 23,6 & 159 & 75,0 \\
\hline 2014 & 3 & 1,6 & 43 & 22,4 & 146 & 76,0 \\
\hline 2015 & 5 & 2,1 & 50 & 21,5 & 178 & 76,4 \\
\hline
\end{tabular}


Пол. Ряд исследователей отмечает различия в заболеваемости колоректальным раком у мужчин и женщин. В структуре онкологической заболеваемости в России (2006 г.) рак прямой кишки составлял 5,3\% у мужчин и 4,7\% у женщин $[2,12]$. Бутенко А.В. и соавторы отмечают, что у мужчин колоректальный рак встречается чаще, чем у женщин [2]. Алиев В.А. и соавторы сообщают о росте коэффициента риска возникновения рака ободочной кишки, для женщин, достигших возраста пременопаузы [1]. Чиссов В.И. и соавторы (2015) считают, что заболеваемость колоректальным раком мужчин и женщин сопоставима, а пик заболеваемости приходится на возраст старше 65 лет $[11,13]$.

Мы изучили частоту КРР у женщин и мужчин. Установлено, что на протяжении 10 лет в Хакасии доля женщин (52,5\%) преобладает над долей мужчин (47,5\%) (уровень статистической значимости р $<0,05)$. В Республике Хакасия, как и в Российской Федерации, на протяжении двух последних десятилетий сложилась уникальная диспропорция средней продолжительности жизни мужчин и женщин. Показатели средней продолжительности жизни у женщин превышают показатели средней продолжительности у мужчин на десять и более лет (табл. 2), что также может влиять на преобладание женщин среди пациентов с КРР в Хакасии на 1-5\%.

Таблица 2.

Распределение пациентов с колоректальным раком в зависимости от пола и в контексте средней продолжительности жизни мужчин и женщин в Хакасии в период с 2006 по 2015 годы

\begin{tabular}{|c|c|c|c|c|c|c|}
\hline \multirow{3}{*}{ Годы } & \multicolumn{4}{|c|}{ Количество больных } & \multirow{2}{*}{\multicolumn{2}{|c|}{$\begin{array}{c}\text { Средняя продолжитель- } \\
\text { ность жизни в Республи } \\
\text { ке Хакасия, годы }\end{array}$}} \\
\hline & \multicolumn{2}{|c|}{ мужчины } & \multicolumn{2}{|c|}{ женщины } & & \\
\hline & $\begin{array}{c}\text { Абсолютные } \\
\text { числа } \\
\end{array}$ & Доля,\% & $\begin{array}{c}\text { Абсолютные } \\
\text { числа } \\
\end{array}$ & Доля,\% & Мужчины & Женщины \\
\hline 2006 & 69 & \begin{tabular}{|l|l|}
53,9 \\
\end{tabular} & 59 & 46,1 & 58,1 & 69,9 \\
\hline 2007 & 46 & 36,5 & 80 & 63,5 & 60,4 & 72,2 \\
\hline 2008 & 81 & 46,8 & 92 & 53,2 & 60,8 & 72,4 \\
\hline 2009 & 70 & 48,6 & 74 & 51,4 & 61,6 & 72,9 \\
\hline 2010 & 90 & 50,3 & 89 & 49,3 & 61,7 & 73,0 \\
\hline 2011 & 79 & 46,7 & 90 & 53,3 & 62,0 & 73,5 \\
\hline 2012 & 99 & 48,1 & 107 & 51,9 & 61,9 & 73,5 \\
\hline 2013 & 92 & 46,9 & 104 & 53,1 & 62,9 & 74,1 \\
\hline 2014 & 79 & 48,2 & 85 & 51,8 & 63,0 & 74,7 \\
\hline 2015 & 101 & 49,3 & 104 & 50,7 & 63,4 & 73,8 \\
\hline
\end{tabular}


Клиника. По данным историй болезней, в большинстве случаев отмечалось длительное латентное течение КРР, при прогрессировании процесса появлялись признаки заболевания, связанные с непроходимостью кишки, кровопотерей или неспецифическими симптомами опухолевого процесса. Наиболее частыми симптомами были: боль в нижних отделах живота (92,2\%); патологические примеси в кале - кровь и слизь $(80 \%)$; запоры (78,9\%). Триада признаков: слабость, тенезмы и снижение массы тела - регистрировалась со следующей частотой: $68,3 \% ; 49,4 \%$ и $35,5 \%$ соответственно. Значительно реже отмечались диарея, чувство инородного тела в кишке, анемия.

Генетические факторы риска имеют значение, как в случае спорадического КРР, так и в случае наследственных форм КРР. Спорадический КРР относится к тем случаям, когда у заболевших индивидуумов может быть выявлена наследственная отягощенность, но может и отсутствовать семейный анамнез КРР. Мы изучили этот аспект витального анамнеза среди госпитального контингента с КРР. Родственников первой и второй степени родства с раком любой локализации имели $39,4 \%$ пациентов, из них наследственность по КРР была подтверждена у 18,2\% пациентов. Кроме того, некоторые пациенты $(4,5 \%)$ уже реализовали «наследственный потенциал» до появления КРР и имели в анамнезе рак иной локализации.

Спорадические формы КРР относят к полигенным заболеваниям, «эпидемия» которых во многом связана с образом жизни, он на 54-60\% определяет состояние здоровья человека, и появление вследствие этого конвенционных факторов риска. Мы изучили частоту и экспрессию факторов риска по данным витального анамнеза пациентов с КРР, чтобы составить представление о фенотипе пациента.

Стратификация индекса массы тела. Риск развития КРР у пациентов с ожирением в 1,5 раза выше, чем у людей с нормальной массой тела. Изучая частоту этого фактора риска среди госпитального контингента с КРР, мы установили, что индекс массы тела (ИМТ) по формуле Кетле, в

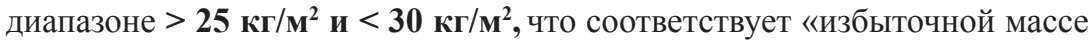
тела», по классификации ВОЗ, выявлен у $\mathbf{4 0 , 9 \%}$ пациентов. ИМТ > 30

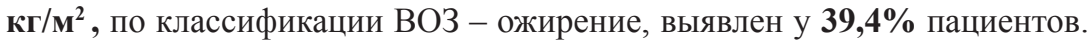
Нормальный показатель ИМТ (18,5-24,99 кг/м²) до развития КРР имелся у $\mathbf{1 9 , 7 \%}$ пациентов. Ожирение и избыточная масса тела являются частым фактором риска $(81,3 \%)$, среди мужчин статистически значимо чаще диагностировали избыточную массу тела $(30,3 \%, \mathrm{p}<0,05)$, а среди женщин ожирение разной степени $(33,3 \%, \mathrm{p}<0,05)$ (табл. 3$)$. 
Кроме того, при проведении корреляционного анализа было выявле-

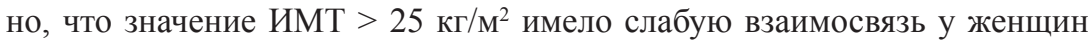
с КРР и СД 2 типа $(\mathrm{r}=0,58, \mathrm{p}<0,05)$. У мужчин аналогичная зависимость отсутствовала.

Таблица 3.

\section{Распределение пациентов с колоректальным раком в зависимости от индекса массы тела и пола}

\begin{tabular}{|c|c|c|c|c|}
\hline $\begin{array}{c}\text { Индекс массы тела } \\
\text { по формуле Кетле }\end{array}$ & $\begin{array}{c}\text { Все пациенты, } \\
\text { \% }\end{array}$ & $\begin{array}{c}\text { Мужчины, } \\
\text { \% }\end{array}$ & $\begin{array}{c}\text { Женщины, } \\
\text { \% }\end{array}$ & $\mathbf{p}$ \\
\hline Нормальная масса тела & 19,7 & 7,6 & 12,1 & 0,346 \\
\hline Избыточная масса тела & 40,9 & 30,3 & 10,6 & 0,0009 \\
\hline Ожирение & 39,4 & 6 & 33,3 & 0,0001 \\
\hline
\end{tabular}

Примечание: $\mathrm{p}$ - уровень статистической значимости показателя при сравнении у мужчин и женщин, достоверность статистической значимости различий при $\mathrm{p}<0,05$.

Отсутствие физической активности, курение табака и употребление алкоголя. У людей, ведущих малоподвижный образ жизни, чаще выявляют избыточный вес и ожирение $[5,6,16,21]$. Оба фактора симультанно связаны с повышением уровня инсулина, медиаторов системного воспаления и риском развития КРР. Мы выявили гиподинамию у 18,9\% пациентов с КРР, мужчины имели этот фактор риска в 5 раз чаще, чем женщины 15,2 и 3,0 \% соответственно ( $<<0,05)$.

Химические соединения, образующиеся при курении табака, относятся к канцерогенам 1-го порядка, способствуют развитию рака пищевода, желудка и толстой кишки $[14,17]$. Риск КРР повышается в связи с интенсивностью курения (выкуривание 40 сигарет в день повышает риск КРР на $38 \%$, а 60 пачек сигарет в год - на 51\%) и длительностью курения (курение более 40 лет повышает риск КРР на 20\%). Среди госпитального контингента курящими были 33,3\% пациентов с КРР (индекс пачка/лет=14), доля курящих мужчин в два раза больше, чем доля женщин (индекс пачка/лет=10) - 24,3\% и 12,1\% соответственно ( $<0,05)$. Корреляционный анализ показал: у пациентов с КРР между полом и курением имеется слабая прямопропорциональная зависимость $(\mathrm{r}=0,57, \mathrm{p}<0,05)$.

Канцерогенными свойствами обладает метаболит алкоголя - ацетальдегид [15]. Степень риска развития КРР зависит от количества потребляемого 
алкоголя: регулярное употребление алкоголя $\geq 45$ г/день приводит к увеличению риска КРР; умеренное употребление алкоголя (12,6-49,9 г/день этилового спирта) повышает риск на $21 \%$, а значительное ( $\geq 50$ г/день) - на $52 \%$. Среди госпитального контингента с КРР мы выявили этот фактор риска у $68,2 \%$ пациентов, в том числе у $37,9 \%$ мужчин и $30,3 \%$ женщин (табл. 4).

Таблицча 4.

Доля пациентов с колоректальным раком в зависимости от пола и отсутствием физической активности, курением табака и употреблением алкоголя

\begin{tabular}{|c|c|c|c|c|}
\hline Показатель & $\begin{array}{c}\text { Все пациенты, } \\
\text { \% }\end{array}$ & $\begin{array}{c}\text { Мужчины, } \\
\text { \% }\end{array}$ & $\begin{array}{c}\text { Женщины, } \\
\mathbf{\%}\end{array}$ & $\mathbf{p}$ \\
\hline Гиподинамия & 18,9 & 15,2 & 3,0 & 0,003 \\
\hline Курение & 33,3 & 24,3 & 12,1 & 0,02 \\
\hline Алкоголь & 68,2 & 37,9 & 30,3 & 0,39 \\
\hline
\end{tabular}

Примечание: $\mathrm{p}$ - уровень статистической значимости показателя при сравнении у мужчин и женщин, достоверность статистической значимости различий при $\mathrm{p}<0,05$.

Фоновая и сопутствующая соматическая патология также вносят определенный вклад в реализацию канцерогенного потенциала при развитии спорадического КРР. Для КРР и СД 2 типа характерна генетическая многофакторность и общие популяционные факторы риска. Среди госпитального контингента с КРР, сахарным диабетом 2 типа страдало $15,1 \%$ пациентов, из них женщин было в 4 раза больше, чем мужчин ( $12,1 \%$ и $3 \%$ соответственно). Холецистэктомию по поводу жёлчекаменной болезни (ЖКБ) имели 10,6\% пациентов, женщин в 2,5 раза больше, чем мужчин. Все три заболевания (КРР, СД 2 типа, ЖКБ) выявлены у 6\% пациентов; женщины $(4,5 \%)$ в 3 раза чаще имели сочетанную патологию, в отличие от мужчин $(1,5 \%)$. Длительный анамнез по ВЗК фиксируется 5 раз чаще у женщин $(7,6 \%)$, чем у мужчин $(1,5 \%, \mathrm{p}<0,05)$ (табл. 5$)$.

Модели стадийного перехода: «аденома-карцинома» Т. Мyto, «гиперплазия - карцинома» J.R. Jass - дают теоретическое обоснование патогенеза КРР. Мы изучили частоту предраковых изменений слизистой оболочки толстой кишки среди госпитального контингента с КРР. Установлена достоверная связь заболевания с предшествующими полипами, которые регистрировались в 40,3\% случаев КРР. Наиболее частой локализацией полипов, как и КРР, являются прямая кишка и сигмовидный отдел ободочной кишки. Все полипы были морфологически идентифицированы, в $86,9 \%$ случаев, как аденокарцинома. 
Таблицуа 5.

Особенности сопутствующей и фоновой патологии у госпитального контингента с колоректальным раком за 2017 год

\begin{tabular}{|c|c|c|c|c|}
\hline $\begin{array}{c}\text { Сопутствующая } \\
\text { патология }\end{array}$ & $\begin{array}{c}\text { Все пациенты, } \\
\text { \% }\end{array}$ & $\begin{array}{c}\text { Мужчины, } \\
\text { \% }\end{array}$ & $\begin{array}{c}\text { Женщины, } \\
\text { \% }\end{array}$ & $\mathbf{p}$ \\
\hline $\begin{array}{c}\text { Сахарный диабет } \\
\text { 2 типа }\end{array}$ & 15,1 & 3,0 & 12,1 & 0,15 \\
\hline $\begin{array}{c}\text { ЖКБ, } \\
\text { холецистэкстомия }\end{array}$ & 10,6 & 3,0 & 7,6 & 0,12 \\
\hline $\begin{array}{c}\text { Воспалительные заболева- } \\
\text { ния кишечника }\end{array}$ & 9,1 & 1,5 & 7,6 & 0,05 \\
\hline $\begin{array}{c}\text { ЖКБ, холецистэкстомия и } \\
\text { сахарный диабет 2 типа }\end{array}$ & 6,0 & 1,5 & 4,5 & 0,24 \\
\hline
\end{tabular}

Примечание: $\mathrm{p}$ - уровень статистической значимости показателя при сравнении у мужчин и женщин, достоверность статистической значимости различий при $\mathrm{p}<0,05$.

У пациентов, имевших полипы слизистой оболочки толстой кишки, установлена взаимосвязь с приемом алкоголя $(\mathrm{r}=0,47, \mathrm{p}<0,05)$ и низким уровнем физической активности $(\mathrm{r}=0,47, \mathrm{p}<0,05)$ в анамнезе. При анализе характера данной зависимости от пола выявлено, что взаимосвязь полипов и приема алкоголя, а также полипов и физической активности характерно только для мужчин $(\mathrm{r}=0,41$ и $\mathrm{r}=0,62$, соответственно, $\mathrm{p}<0,05)$. В то время как у женщин прием алкоголя имел обратно пропорциональную взаимосвязь с сахарным диабетом 2 типа $(\mathrm{r}=-0,38, \mathrm{p}<0,05)$, а гиподинамия слабую статистическую взаимосвязь с ВЗК ( $\mathrm{r}=0,48, \mathrm{p}<0,05)$.

\section{Заключение}

Увеличение показателей заболеваемости КРР в Республике Хакасия имеет амбивалентное значение, так как одновременно обусловлено следующими факторами: увеличение первичной заболеваемости, в том числе за счет активно выявленных пациентов; увеличение доли пациентов с впервые установленным диагнозом КРР на 1-2 стадиях заболевания, повышение пятилетней выживаемости пациентов. Кроме того увеличение заболеваемости КРР может отражать разные аспекты, включая жизнедеятельность человека, изменение типа питания, повышение среднего популяционного возраста населения и индекса массы тела, повышение распространенности курения. Эффективность ранней диагностики заболевания предполагает учет фенотипических особенностей и особенностей витального анамнеза пациентов, которые следует связать с высоким риском развития КРР. 


\section{Сиисок литературы}

1. Алиев В.А., Расулов А.О., Маргарян А.Г., Барсуков Ю.А. Современные возможности лечения метастатического колоректального рака // Вестник РОНЦ им. Н. Н. Блохина РАМН. 2015. №26(1). С. 15-22.

2. Бутенко А.В., Разбин В.Н. Рак прямой кишки. Современные направления и тенденции в лечении. Обзор литературы // Сибирский онкологический журнал. 2011. №48(6). С. 83-89.

3. Возрастно-половые, этнические и морфологические особенности колорекитального рака в семейном регионе / К.Т. Жбагин, Ю.М. Семенова, М.А. Даулетьярова и др. // Medicine (Almaty). 2016. №10 (172). С. 20-22.

4. Ганцев Ш.Х. Онкология: учебник / Ш.Х. Ганцев, М.И. Давыдов. М.: Медицина. 2010. $920 \mathrm{c.}$

5. Животовский А.С., Кутихин А.Г., Брусина Е.Б., Цитко Е.А. Эпидемиология колоректального рака: обзор факторов риска // Эпидемиология и вакцинопрофилактика. 2013. №1 (68). С. 58-64.

6. Жунусова Г.С. Разработка панелей генетических маркеров для скрининга семейных и спорадических случаев колоректального рака в казахстанских популяциях: дисс.... доктора философии. Астана, 2014. $125 \mathrm{c}$.

7. Клинические рекомендации по диагностике и лечению больных раком прямой кишки, 2014. http://oncology-association.ru/docs/recomend/dec2015/41vzrek.pdf (дата обращения 8.12.2016).

8. Кушлинский Н.Е., Исаков В.А., Делекторская В.В., Кусаинов Г.Х., Гольдберг В.Е. Обзоры колоректальный рак. опухолевые маркеры и молекулярно-генетические методы диагностики // Сибирский онкологический журнал. 2004. №2-3. С. 134-148.

9. Молекулярные маркеры чувствительности и резистентности карцином толстой кишки к терапии антагонистами EGFR / A.О. Иванцов, Г.А. Янус, Е.Н. Суспицин и др. // Сибирский онкологический журнал. 2016. Т.15, №1. C. 59-66. DOI: 10.21294/1814-4861-2016-15-1-59-66

10. Новиков А.И., Массард Ж. Онкологические заболевания органов брюшной полости: учебное пособие. Омск: Издательство Центра МО и ИТОмГМA 2008. С. 112-148.

11. Практическое руководство Всемирного гастроэнтерологического общества и Международного союза по профилактике рака пищеварительной системы: Скрининг колоректального рака, 2008. http://www.worldgastroenterology.org/UserFiles/file/guidelines/colorectal-cancer-screening-russian-2008.pdf (дата обращения 8.12.2016). 
12. Циммерман Я.С. Колоректальный рак: современное состояние проблемы // Российский журнал гастроэнтерологии, гепатологии, колопроктологии. 2012. №4. С. 5-16.

13. Чиссов В.И. Онкология: клинические рекомендации. М.: ГЭОТАР-МЕДИА, 2015. 638 с.

14. Abrams J.A. Cigarette smoking and the colorectal adenoma-carcinoma sequence / J.A. Abrams, M.B. Terry, A.I. Neugut // Gastroenterology. 2008. V. 2, pp. 617-619.

15. Alcohol attributable burden of incidence of cancer in eight European countries based on resultsfrom prospective cohort study / M. Schutze, H. Boeing, T. Pischon et al. // BMJ. 2011. V. 342. P. 1584.

16. Chan A.T. Primary prevention of colorectal cancer / A.T. Chan, E.L. Giovannucci // Gastroenterology. 2010. V. 6, pp. 2029-2043.

17. Cigarette smoking and adenomatous polyps: a meta-analysis / E. Botteri, S. Iodice, S. Raimondi et al. // Gastroenterology. 2008. V. 2, pp. 388-395.

18. Effects of KRAS, BRAF, NRAS, and PIK3CA mutations on the efficacyof cetuximab plus chemotherapy in chemotherapy-refractory metastatic colorectal cancer: a retrospective consortium analysis / De Roock W., Claes B., Bernasconi D., et al // Lancet Oncol. 2010. Vol. 11 (8), pp. 753-762. doi: 10.1016/S14702045(10)70130-3.

19. Extended RAS analysis for anti-epidermal growth factor therapy in patients with metastatic colorectal cancer / J.R. Hecht, J.Y. Douillard, L. Schwartzberg, et al // Cancer Treat. Rev. 2015. Vol. 41 (8), pp. 653-659. doi: 10.1016/j. ctrv.2015.05.008.

20. Mutant KRAS codon 12 and 13 alleles in patients with metastatic colorectal cancer: assessment as prognostic and predictive biomarkers of response to panitumumab / M. Peeters, J.Y. Douillard, E. Van Cutsem, et al // J. Clin. Oncol. 2013. Vol. 31 (6), pp. 759-765. doi: 10.1200/JCO.2012.45.1492/

21. Wolin K.Y., Yan Y., Colditz G.A., Lee I.M. Physical activity and colon cancer prevention: a meta-analysis // Br. J. Cancer. 2009. V 4. P. 611-616. doi: $10.1038 /$ sj.bjc. 6604917

\section{References}

1. Aliev V.A., Rasulov A.O., Margaryan A.G., Barsukov Yu.A. Sovremennye vozmozhnosti lecheniya metastaticheskogo kolorektal'nogo raka [Modern possibilities of treatment of metastatic colorectal cancer]. Vestnik RONTs im. N.N. Blokhina RAMN. 2015. № 26 (1), pp. 15-22.

2. Butenko A.V., Razbin V.N. Rak pryamoy kishki. Sovremennye napravleniya i tendentsii v lechenii. Obzor literatury [Rectal cancer. Modern trends and trends in treatment. A review of the literature]. Sibirskiy onkologicheskiy zhurnal. 2011. №48 (6), pp. 83-89. 
3. Zhbagin K.T., Semenova Yu.M., Daulet'yarova M.A. et al. Vozrastno-polovye, etnicheskie i morfologicheskie osobennosti kolorekital'nogo raka v semeynom regione [Age-sex, ethnic and morphological features of colorectal cancer in the family region]. Medicine (Almaty). 2016. No. 10 (172), pp. 20-22.

4. Gantsev Sh.H., Davydov M.I. Onkologiya [Oncology]: textbook. M.: Medicine. 2010. 920 p.

5. Zhivotovskiy A.S., Kutikhin A.G., Brusina E.B., Tsitko E.A. Epidemiologiya kolorektal'nogo raka: obzor faktorov riska [Epidemiology of colorectal cancer: an overview of risk factors]. Epidemiologiya i vaktsinoprofilaktika [Epidemiology and vaccine prevention]. 2013. № 1 (68), pp. 58-64.

6. Zhunusova G.S. Razrabotka paneley geneticheskikh markerov dlya skrininga semeynykh i sporadicheskikh sluchaev kolorektal'nogo raka $v$ kazakhstanski$k h$ populyatsiyakh [Development of panels of genetic markers for screening of family and sporadic cases of colorectal cancer in Kazakhstan populations]: diss .... Doctor of Philosophy. Astana, 2014. 125 p.

7. Clinical recommendations for the diagnosis and treatment of patients with colorectal cancer, 2014. http://oncology-association.ru/docs/recomend/dec2015/41vZrek.pdf (circulation date 8.12.2016).

8. Kushlinskiy N.E., Isakov V.A., Delektorskaya V.V., Kusainov G.Kh., Gol'dberg V.E. Obzory kolorektal'nyy rak. opukholevye markery i molekulyarno-geneticheskie metody diagnostiki [Reviews of colorectal cancer. tumor markers and molecular genetic methods of diagnosis]. Sibirskiy onkologicheskiy zhurnal [Siberian Oncological Journal]. 2004. № 2-3, pp. 134-148.

9. Ivantsov A.O., Yanus G.A., Suspitsin E.N. et al. Molekulyarnye markery chuvstvitel'nosti i rezistentnosti kartsinom tolstoy kishki k terapii antagonistami EGFR [Molecular markers of sensitivity and resistance of colon carcinoma to therapy with EGFR antagonists]. Sibirskiy onkologicheskiy zhurnal [Siberian Oncological Journal]. 2016. V.15, №1, pp. 59-66. DOI: 10.21294/1814-4861-2016-15-1-59-66

10. Novikov A.I., Massard Zh. Onkologicheskie zabolevaniya organov bryushnoy polosti [Oncological diseases of the abdominal cavity]: textbook. Omsk: Publishing house of the MO Center and ITOMGMA 2008, pp. 112-148.

11. Practical guidelines of the World Gastroenterological Society and the International Union for the Prevention of Cancer of the Digestive System: Screening for colorectal cancer, 2008. http://www.worldgastroenterology.org/UserFiles/file/guidelines/ colorectal-cancer-screening-russian-2008.pdf ( date of circulation on 8.12.2016).

12. Tsimmerman Ya.S. Kolorektal'nyy rak: sovremennoe sostoyanie problem [Colorectal cancer: the current state of the problem]. Rossiyskiy zhurnal gastroenterologii, gepatologii, koloproktologii [Russian Journal of Gastroenterology, Hepatology, Coloproctology]. 2012. № 4, pp. 5-16. 
13. Chissov V.I. Onkologiya: klinicheskie rekomendatsii [Oncology: clinical recommendations]. Moscow: GEOTAR-MEDIA, 2015. 638 p.

14. Abrams J.A., Terry M.B., Neugut A.I. Cigarette smoking and the colorectal adenoma-carcinoma sequence [Cigarette smoking and the colorectal adenoma-carcinoma sequence]. Gastroenterology [Gastroenterology]. 2008. V. 2, pp. 617-619.

15. Schutze M., Boeing H., Pischon T. et al. Alcohol attributable burden of incidence of cancer in eight European countries based on the results from a prospective cohort study. BMJ. 2011. V. 342. P. 1584.

16. Chan A.T., Giovannucci E.L. Primary prevention of colorectal cancer. Gastroenterology. V. V, pp. 2029-2043.

17. Botteri E., Iodice S., Raimondi S. et al. Cigarette smoking and adenomatous polyps: a meta-analysis. Gastroenterology. 2008. V. 2, pp. 388-395.

18. De Roock W., Claes B., Bernasconi D., et al. Effects of KRAS, BRAF, NRAS, and PIK3CA mutations on the efficacy of cetuximab plus chemotherapy in chemotherapy-refractory metastatic colorectal cancer: a retrospective consortium analysis. Lancet Oncol. 2010. Vol. 11 (8), pp. 753-762. doi: 10.1016 / S14702045 (10) 70130-3.

19. Hecht J.R., Douillard J.Y., Schwartzberg L., et al. Extended RAS analysis for anti-epidermal growth factor in patients with metastatic colorectal cancer. Cancer Treat. Rev. 2015. Vol. 41 (8), pp. 653-659. doi: 10.1016/j. ctrv.2015.05.008.

20. Peeters M., Douillard J.Y., Cutsem E. Van, et al. Mutant KRAS codon 12 and 13 alleles in patients with metastatic colorectal cancer: assessment as prognostic and predictive biomarkers of response to panitumumab. J. Clin. Oncol. 2013. Vol. 31 (6), pp. 759-765. doi: 10.1200 / JCO.2012.45.1492 /

21. Wolin K.Y., Yan Y., Colditz G.A., Lee I.M. Physical activity and colon cancer prevention: a meta-analysis. Br. J. Cancer. 2009. V 4, pp. 611-616. doi: 10.1038/sj.bjc.6604917

\section{ДАННЫЕ ОБ АВТОРАХ}

Штыгашева Ольга Владимировна, доктор медицинских наук

Хакасский государственныии университет им. Н.Ф. Катанова nр-т Ленина, 90, г. Абакан, 655000, Республика Хакасия, Российская Федераиия

olgashtygasheva@rambler.ru

Агеева Елизавета Сергеевна, доктор медицинских наук Хакасский государственный университет им. Н.Ф. Катанова 
пр-т Ленина, 90, г. Абакан, 655000, Республика Хакасия, Российская Федераиия ageevaeliz@rambler.ru

Балобина Наталья Сергеевна, ординатор по специальности Терапия 2 года обучения

Хакасский государственный университет им. Н.Ф. Катанова nр-т Ленина, 90, г. Абакан, 655000, Республика Хакасия, Российская Федерация

Fflorum@yandex.ru

Манашева Дилия Исмагиловна, ординатор по специальности Терапия 1 года обучения Хакасский государственныии университет им. Н.Ф. Катанова пр-т Ленина, 90, г. Абакан, 655000, Республика Хакасия, Российская Федерачия diliya170793@mail.ru

\section{DATA ABOUT THE AUTHORS}

Shtygasheva Olga Vladimirovna, Doctor of Medical Sciences

Katanov Khakass State University

90, Lenin Pr, Abakan, 655000, Russian Federation olgashtygasheva@rambler.ru

Ageeva Elizaveta Sergeevna, Doctor of Medical Sciences Katanov Khakass State University 90, Lenin Pr, Abakan, 655000, Russian Federation ageevaeliz@rambler.ru

Balobina Natalya Sergeevna, Resident in the Field of Second-Year Therapy Katanov Khakass State University 90, Lenin Pr, Abakan, 655000, Russian Federation Ffllorum@yandex.ru

Manasheva Diliya Ismagilovna, Resident in the Field of First-Year Therapy Katanov Khakass State University 90, Lenin Pr, Abakan, 655000, Russian Federation diliya170793@mail.ru 